\title{
UMA VIDA DE DEDICAÇÃO À GINÁSTICA: INSPIRANDO GERAÇÕES
}

Entrevista realizada com a Profa. Dra. Elizabeth Paoliello, Faculdade de Educação Física - Universidade Estadual de Campinas - UNICAMP, Campinas, São Paulo Brasil

Entrevistadora: Profa. Dra. Eliana Ayoub, Faculdade de Educação - Universidade Estadual de Campinas - UNICAMP, Campinas, São Paulo - Brasil

Colaboração: Prof. Dr. Marco A. C. Bortoleto - Faculdade de Educação Física Universidade Estadual de Campinas - UNICAMP, Campinas, São Paulo - Brasil

\section{APRESENTAÇÃO}

Considerada uma das mais importantes pesquisadoras e promotoras da ginástica no Brasil, a professora Elizabeth Paoliello conseguiu combinar ao longo de sua experiência de mais de 40 anos, atividades como docência em escolas, clubes e universidades, orientação de trabalhos acadêmicos, publicação de artigos e livros, coordenação de grupo de pesquisa e organização de importantes eventos em âmbito regional, nacional e internacional.

Sua paixão pela ginástica vem inspirando gerações de estudantes, professores e pesquisadores para a prática, o estudo e o ensino da ginástica nos mais diferentes espaços educativos, construindo assim um legado que merece nosso respeito, admiração e registro público.

Por tudo isso e pelo fato do Grupo de Pesquisa em Ginástica estar comemorando 20 anos em 2013, decidimos realizar esta entrevista que traz momentos marcantes da trajetória profissional da professora Beth, o que, com certeza, servirá igualmente de inspiração aos leitores da Revista Conexões.

\section{Prezada professora, poderia narrar como se deu sua inserção na área da} ginástica?

Ainda aluna do ensino fundamental, antigo ginásio, no Colégio Culto à Ciência em Campinas - SP, tive meu primeiro contato com a ginástica artística nas aulas de Educação Física (EF). Mas ainda não era uma escolha, pois, eu me encantava com todas as modalidades que o colégio oferecia e sentia enorme prazer na prática esportiva. Esse colégio era uma referência na área da EF e lá tive também a oportunidade de iniciar 
aulas de ballet e dança o que futuramente me ajudaram muito na atuação com a ginástica. Foi no curso de graduação em Educação Física na Pontifícia Universidade Católica de Campinas (PUCC) que me apaixonei pela ginástica nas aulas com a professora Neila Miessa, especialmente a ginástica rítmica que possibilitava a utilização dos recursos que o ballet e a dança me proporcionaram. Fui monitora das disciplinas de ginástica durante o curso e um ano após a minha formatura fui convidada a assumir as aulas, pois a referida professora teve de se afastar. Fiz parte do corpo docente da Faculdade de Educação Física da PUCC (FAEFI) por 16 anos, onde construí a base do meu conhecimento docente na área. Em 1987, ingressei na Faculdade de Educação Física da UNICAMP (FEF), onde atuei como docente e pesquisadora até 2004 (ano de minha aposentadoria), mantendo até a presente data meu vínculo junto ao Grupo de Pesquisa em Ginástica.

\section{Conte-nos alguns aspectos importantes da sua carreira profissional e acadêmica no âmbito da ginástica.}

Além de minha atuação como professora universitária fui, simultaneamente, técnica e árbitra de ginástica rítmica no Clube Campineiro de Regatas e Natação por 8 anos e professora de ginástica estética para mulheres, antiga denominação da atual ginástica de condicionamento. Na UNICAMP, atuei como professora em diferentes disciplinas de ginástica e juntamente com a Profa. Dra. Vilma Leni-Nista Piccolo fundei o Grupo Ginástico Unicamp (GGU), que no próximo ano comemora 25 anos de atividade ininterrupta. Publiquei dois livros: "Ginástica Geral: experiências e reflexões" (2008) e "Possibilidades da Ginástica Rítmica" (2010) em parceria com a Profa. Dra. Eliana de Toledo, ambos pela Phorte Editora.

\section{Considerando sua longa experiência profissional, quais são os momentos mais marcantes de sua trajetória na ginástica?}

Posso dizer que todas as experiências vividas nos diversos âmbitos onde atuei foram importantes e ajudaram a construir o meu caminho acadêmico. Mas posso destacar a conclusão do meu mestrado em EF na Unicamp intitulado "A Busca do Autoconhecimento através da Consciência Corporal: uma nova tendência" que tratava de um movimento "alternativo" das práticas gímnicas, o qual teve grande influência da proposta de "Anti-Ginástica" desenvolvida por Thérése Bertherat na década de 1970/1980 no Brasil. Dando continuidade à minha formação acadêmica, em 1997, Conexões: revista da Faculdade de Educação Física da UNICAMP, Campinas, v. 11, n. 3, p. 202-207, jul./set. 2013. 
defendi a minha tese de doutorado sob o título "Ginástica Geral: uma área do conhecimento da Educação Física" que foi um marco nesta área e fundamentou uma série de pesquisas que posteriormente foram sendo realizadas, não apenas na UNICAMP mas em diversas universidades do país. Essa etapa me possibilitou a criação do Grupo de Pesquisa em Ginástica juntamente com o Prof. Dr. Jorge Sergio Pérez Gallardo no ano de 1993 e que neste ano comemora 20 anos de atividades com um Seminário Internacional a ser realizado no dia 10 de outubro. Atualmente, o Grupo de Pesquisa em Ginástica é coordenado por mim e pelo Prof. Dr. Marco A. C. Bortoleto.

\section{Especificamente no âmbito universitário, como você analisa as suas contribuições para a formação do profissional da educação física?}

Atuei por 30 anos como professora das disciplinas de ginástica e durante esse tempo procurei encantar meus alunos com a ginástica e prepará-los para que pudessem desenvolver esse conhecimento entre seus alunos nas escola, clubes, academias e demais espaços onde fossem atuar. Além das disciplinas de graduação e orientação de trabalhos de iniciação científica e de conclusão de curso, organizei e ministrei cursos de especialização para professores, além de inúmeras palestras e cursos em várias instituições pelo país e no exterior. Na pós-graduação, tive o prazer de orientar alunos no mestrado e doutorado, que fortaleceram com suas pesquisas o conhecimento da área da ginástica e ampliaram a sua abrangência, ao levarem-no para suas universidades de origem. O oferecimento de projetos de extensão também pode ser considerado um ponto relevante na formação profissional de nossos alunos, que tiveram a oportunidade de vivenciar a prática didática e estruturar a sua futura atuação docente.

\section{Desde a criação do Grupo Ginástico Unicamp (GGU) em 1989 e do Grupo de} Pesquisa em Ginástica em 1993, quais têm sido as ações desses grupos na esfera da ginástica?

O Grupo Ginástico Unicamp pode ser considerado, após 25 anos de atuação, como um grupo de referência tanto nacional como internacionalmente. Por ele já passaram mais de 200 integrantes vindos da $\mathrm{EF}$ ou de outros cursos, que tiveram a oportunidade de conhecer e viver a ginástica geral (GG), na qual a vivência de valores humanos é o principal objetivo. Este grupo que hoje é coordenado pelo Prof. Dr. Marco Antonio C. Bortoleto e pela Profa. Ms. Larissa Graner tem realizado durante todos esses anos inúmeras apresentações em escolas, clubes, associações e festivais, levando sua Conexões: revista da Faculdade de Educação Física da UNICAMP, Campinas, v. 11, n. 3, p. 202-207, jul./set. 2013. 
proposta de GG e motivando a prática e a criação de novos grupos. Realizou mais de 15 viagens internacionais e participou dos mais importantes festivais no mundo. No próximo mês de novembro viajará para Hong Kong e Japão a convite de universidades e das federações de ginástica desses países, o que reforça o reconhecimento internacional que o grupo alcançou.

Quanto às ações desenvolvidas pelo Grupo de Pesquisa em Ginástica ressalto o desenvolvimento de projetos de pesquisa que têm contribuído para o fortalecimento da área dando subsídios para a melhoria da formação profissional e da prática da ginástica gerando novas investigações. Outro setor de grande repercussão é a organização de eventos como as 6 edições do Fórum Internacional de Ginástica, realizado a cada dois anos em parceria com o SESC São Paulo e o apoio internacional da International Sport and Culture Association (ISCA) e as 3 edições do Seminário Internacional de Ginástica Artística e Rítmica de Competição (SIGARC).

\section{No momento atual, estamos diante de um intenso incentivo à internacionalização acadêmica. Você poderia nos relatar desde quando e como vem ocorrendo o processo de interlocução internacional do GGU e quais os seus desdobramentos?}

Nosso primeiro contato internacional ocorreu em 1994, quando recebemos na FEF/UNICAMP um grupo dinamarquês de ginástica coordenado por Holger Vestergaard para a realização de uma apresentação e oficina. Nesta oportunidade, o GGU também se apresentou e ofereceu uma oficina aos convidados mostrando um pouco da cultura brasileira e o nosso jeito de fazer ginástica. A partir desse contato recebemos um convite para participar do Festival de Alicante (Espanha) em 1995, promovido pela Associação Dinamarquesa de Ginástica e Esportes (DGI) seguido de uma viagem, à Dinamarca para apresentações em vários locais. Desde então, o GGU ampliou seus contatos e realizou várias viagens internacionais assim como recebeu professores e grupos estrangeiros de ginástica para curtas temporadas. A filiação da UNICAMP à International Sport and Culture Association (ISCA) abriu as portas para o intercâmbio internacional de nossos alunos num programa denominado "International Youth Leader Education”, que oferece bolsas com duração de 4 a 9 meses em escolas de esportes na Dinamarca. Desde 1997 até a presente data, aproximadamente 100 alunos da FEF/UNICAMP já participaram do programa. 


\section{Em outubro de 2014, ocorrerá o VII Fórum Internacional de Ginástica Geral}

(FIGG) em Campinas/SP. Qual é a importância do Fórum para o desenvolvimento da ginástica no Brasil e no exterior?

O FIGG pode ser considerado como o principal evento da área no continente americano, reunindo profissionais e pesquisadores de todo o Brasil e de vários países. Sua programação inclui a presença de nomes importantes da ginástica internacional em palestras e cursos, de grupos estrangeiros de diferentes países e grupos brasileiros que mostram seus trabalhos nos festivais que compõem a programação. Além disso, o FIGG caracteriza-se como um espaço de apresentação de trabalhos de pesquisa que são publicados nos Anais do evento os quais se transformaram em publicações de referência para professores e estudiosos.

8. Conte-nos o contexto em que ocorreu o convite para ser vice-presidente da International Sports andCultureAssociation- ISCA (a primeira mulher e membro da América do Sul a ocupar esse espaço) e quais as contribuições do trabalho dessa associação para a ginástica mundial e no Brasil.

Como consequência dos contatos acima citados, fui convidada em 1998 a participar de uma reunião em Vila La Angostura na Argentina, que tinha como objetivo criar um Comitê Latino Americano da ISCA. Passei então a integrar o Comitê Executivo da ISCA e assumi o cargo de presidente do Comitê Latino Americano, hoje denominado ISCA América Latina, no qual permaneço até hoje. Durante os últimos 15 anos, também tive a oportunidade de contribuir na posição de vice-presidente por 4 anos. Foi uma experiência muito enriquecedora e gratificante, na qual pude aprender muito sobre política internacional no esporte, voluntariado, liderança, criação e gestão de projetos e programas em "Esporte para Todos".

A ISCA é uma organização internacional com sede na Dinamarca que atua na área do "Esporte para Todos", movimento este que visa a ampliar e facilitar o acesso da prática de esportes e atividade física para o maior número possível de pessoas. A ginástica é uma das modalidades que compõem esse universo esportivo e que tem sempre o apoio da ISCA nas ações propostas pelas organizações filiadas, como é o caso do FIGG, realizado pela FEF/UNICAMP e SESC, ambos membros da ISCA.

\section{Quais são seus projetos atuais e futuros em relação à ginástica?}

Conexões: revista da Faculdade de Educação Física da UNICAMP, Campinas, v. 11, n. 3, p. 202-207, jul./set. 2013. 
Como mencionei anteriormente, compartilho com o Prof. Dr. Marco A. C. Bortoleto a coordenação do Grupo de Pesquisa em Ginástica da FEF/UNICAMP e neste grupo estamos desenvolvendo uma série de projetos, entre eles o Seminário Internacional de Ginástica em comemoração aos 20 anos do grupo, que será realizado no dia 10 de outubro com a presença de professores e pesquisadores que atuam na área da ginástica. No próximo ano, no mês de outubro, em parceria com o SESC e o apoio internacional da ISCA, promoveremos a sétima edição do Fórum Internacional de Ginástica Geral. Também estamos organizando um livro sobre GG no qual colaboram pesquisadores de vários países, o qual deverá ser lançado no inicio de 2014. Após tantos anos de atuação e experiência na ginástica pretendo me dedicar ainda mais à difusão da GG em nível local, estadual e nacional, contribuindo com ações relativas à formação de professores, organização de eventos e produção de material didático que possam facilitar a atuação docente e ampliar o acesso à GG para o maior número possível de pessoas.

\section{Para finalizar esta entrevista, gostaria que você nos revelasse qual é o seu "segredo" para estar sempre disponível, inspirando, influenciando e abrindo caminhos para tantas pessoas no mundo da ginástica e da Educação Física.}

Eu sou uma pessoa realizada em minha profissão, amo o movimento, a atividade física, a ginástica e me encantam as possibilidades de educar e promover as pessoas por meio deles. Tenho uma grande alegria em poder auxiliar na formação de alunos que, como eu, abraçaram a EF. Acredito no ser humano e no seu potencial e fico feliz em ver seu crescimento tanto pessoal como profissional e poder abrir novos horizontes e possibilidades. Penso que quanto mais pessoas felizes houver neste mundo, melhor ele será. Gosto de congregar pessoas, de promover encontros, de fazer projetos coletivos, de estar perto dos jovens. Acredito que dividir é somar e que o conhecimento é um patrimônio da humanidade e por isso deve ser compartilhado

Contato: Eliana Ayoub ayoubeliana@gmail.com Marco Antônio Coelho Bortoleto bortoleto@fef.unicamp.br 